These letters are selected from rapid responses posted on bmj.com. Selection is usually made 12 days after print publication of the article to which they respond.

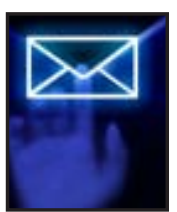

bmj.com To submit a rapid response go to any article on bmj.com and click "respond to this article"

\section{NHS REFORMS}

\section{Author? Author?}

I guess the coalition must have been aware of NHS trusts' concerns before it published the white paper. ${ }^{1}$ Yet again we go through the charade of "consultation." I try not to get upset any more, but one question intrigues me. Who were the coalition's medical advisers in drawing up the plans (if there were any)? I can't find any names in the paper itself and nobody has claimed "credit" publicly.

My impression is of opposition and criticism to the plan from the medical profession, NHS management, and health economists. I have read a few supportive letters from budding entrepreneurs and those wanting to settle old scores, but there has been no systematic enthusiasm.

Governments have used medical advice from interesting sources before, and any government might simply consult an ambitious cadre of

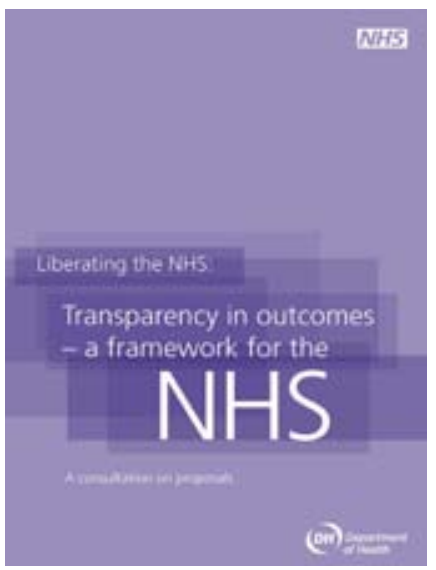

Whatever the patient chooses, there is no gain for me. In the UK capitation based primary care there is no supplier induced demand. What could I possibly gain from sending patients for unnecessary investigations or treatment?

The problem for patients is different. Because there is no direct cost to them, they are likely to opt for even the most marginal benefit from investigations or treatment. I cannot guide patients to the most cost effective option: I can only advise them against interventions likely to be harmful.

If I understand it correctly,

Ruta proposes that GPs should have some financial gain by denying patients care. ${ }^{1}$ However, this increases the chance of patient harm and is likely to affect the poor more than the rich.

The greatest flaw in the proposals is the lack of available tools to match supply and demand sensibly. The white paper has already stated that care will be comprehensive party activists within the profession. But I would like to see if any of the paper's medical sources of inspiration offer to answer questions from the wider profession. If there was no authoritative medical advice, at least the profession can't be blamed when things go badly wrong.

David Levine retired physician, Sennen, Cornwall TR197AX, UK dflreens@hotmail.com

Competing interests: None declared.

1 O'Dowd A. Trusts warn that NHS reforms could cause patient care failures and financial chaos BMJ 2010;341:c5693. (14 October.)

Cite this as: BM/ 2010;341:c6306

\section{New ways to harm patients}

Where has the idea come from that GPs know the cost effectiveness of every intervention during their consultations? ${ }^{1}$

When faced with a clinical problem, I formulate a provisional diagnosis and offer patients the choice of available treatment options. What should I do instead? Omit or misrepresent certain treatment options? The better informed patients will know the available options, and I am likely to be able to fob off only the more deprived patients with inferior healthcare. and remain free at the point of use. If care cannot be denied, if all services have to be commissioned, if GPs cannot introduce user charges, then the only remaining option is lengthy waiting lists.

Waiting lists are inherently inefficient: more consultations for the same problem, more administration, and further advanced illness by the time the patient gets seen. They also create a two tier healthcare system because those who can afford it will go private, increasing health inequalities.

It is an entertaining thought to ruin the GPs who care for the costly poor and ill patients, who never asked to be responsible for managing a budget, and who just wanted to deliver good patient care. I am sure the health service will improve no end if we retain only the GPs who are most skilled in cream skimming the low risk, low cost patients.

Hendrik J Beerstecher GP principal, Sittingbourne, Kent ME10 4JA, UK

hendrick.beerstecher@nhs.net

Competing interests: $\mathrm{HJB}$ is a GP principal.

1 Ruta D. GPs should have to take financial responsibility. BMJ 2010;341:c5613. (14 October.)

Cite this as: BMJ 2010:341:c6308

\section{New ways to harm doctors}

Ruta has not thought about the consequences of his suggestions. ${ }^{1}$ Beerstecher has started to imagine the consequences, ${ }^{2}$ but they would be far worse.

In Germany all outpatient clinics are managed by self employed physicians, GPs, and consultants, who are paid according to how many patients they treat (with a maximum per patient). Doctors who overspend have to explain why and pay the excess-a regress-if their reasons are not accepted. Until 2001 these reasons were listened to and often accepted, but not any more (people on regress committees now have to pay if they do not "regain" enough). So doctors often have to pay back hundreds of thousands of pounds a year, far more than they have earned. They can go to court and appeal, but this is costly.

When treatments might be costly, GPs send patients to a specialist, but because of regress the specialist just sends a letter to the GP with the recommendation, who then thinks, no, not from my budget, and so it goes on. No doctor involved in the patient's care wants his or her budget to be used. This has produced more costs and worse care.

Doctors caring for ill and poor patients have declared bankruptcy and given up their practices after decades of hard work. This is one reason why rural and poorer regions of Germany have too few doctors.

So, when a patient enters your practice you really start to pray: “Please, please, don’t let him or her be ill."

Roswitha-E Goetze-Pelka retired psychiatrist, Fearn, RossShire IV20 1XH, UK

roswitha.gotze-pelka@virgin.net

Competing interests: R-EG-P worked as a neurology and psychiatry specialist in rural Germany for 15 years and has to pay more than $€ 700000$ ( $€ 608300 ; \$ 972900$ ) in regress charges.

1 Ruta D. GPs should have to take financial responsibility. BMJ 2010;341:c5613. (14 October.)

2 Beerstecher HJ. New ways to harm patients. BMJ 2010;341:c6308.

Cite this as: BMJ 2010;341:c6309

\section{GLUCOSAMINE AND OSTEOARTHRITIS}

\section{Effect size is encouraging}

The results and interpretation of the metaanalysis by Wandel and colleagues of the effects of glucosamine and chondroitin on osteoarthritis depend on the trials analysed and the thresholds defined as clinically relevant. ${ }^{1}$ 
The criteria for the selection of trials is questionable; the European Medicines Agency recommends evaluating the analgesic effect of slow acting drugs for osteoarthritis after at least six months of treatment, and the structural effect after two years. ${ }^{2}$ The researchers considered only trials with a minimum of 100 patients per arm. Instead, a scenario analysis should have been performed including smaller studies to assess the effects with and without all the clinical data.

Baseline pain values were not taken into account; a difference of 0.9 units for severe pain (>7) is clinically different from the same difference for pain <4. Indeed, in one of the three trials of chondroitin on disease modification ${ }^{3}$ the baseline pain score was 2.5 , thus unlikely to decrease by $>0.9$.

An effect size of $>0.39$ was arbitrarily defined as clinically relevant. However, effect sizes of $<0.4$ are considered to be clinically meaningful. Indeed, paracetamol is recommended by the European League Against Rheumatism (EULAR) and Osteoarthritis Research Society International (OARSI), yet its effect size is $<0.20$.

Wandel and colleagues conclude that the effect sizes of chondroitin and glucosamine for structure modification are not clinically meaningful. These results contradict another meta-analysis of chondroitin sulphate with the same trials, which showed a difference between placebo and chondroitin in joint space width over two years of $0.13 \mathrm{~mm}(\mathrm{P}=0.0002)$, and an effect size of $0.23(P=0.0001) .{ }^{4}$ In addition, three years of glucosamine sulphate treatment reduces the incidence of knee replacement by $57 \%$ in the next five years, ${ }^{5}$ showing that an effect size of $<0.40$ is clinically meaningful.

Given these limitations, it is inappropriate to conclude that pharmaceutically produced chondroitin and glucosamine should be discouraged for treating osteoarthritis.

Jean-Pierre Pelletier professor of medicine and head, Division of Rheumatology, University of Montreal, Canada dr@jppelletier.ca

Marc C Hochberg professor of medicine and head, Division of Rheumatology and Clinical Immunology, University of

Maryland School of Medicine, USA

Patrick du Souich professor and director, Department of Pharmacology, Faculty of Medicine, University of Montreal,

Canada

André Kahan professor of rheumatology and head, Paris Descartes University, Faculty of Medicine, and Department of Rheumatology A, Cochin Hospital, AP-HP, France

Beat A Michel professor and chair, Department of

Rheumatology and Institute for Physical Medicine, University Hospital Zurich, Switzerland

Competing interests: The authors received research funds and lecture fees from various pharmaceutical companies involved in the treatment of osteoarthritis with chondroitin and/or glucosamine.

The full version of this response is available at www.bmi.com/ content/341/bmj.c4675.full/reply\#bmi_eL_242776.

1 Wandel S, Jüni P, Tendal B, Nüesch E, Villiger PM, Welton $\mathrm{NJ}$, et al. Effects of glucosamine, chondroitin, or placebo in patients with osteoarthritis of hip or knee: network metaanalysis. BMJ 2010;341:c4675. (16 September.)
2 Committee for Products for Medicinal Use. Guideline on clinical investigation of medicinal products used in the treatment of osteoarthritis. CPMP/EWP/784/97 Rev 1; 23 April 2009.

3 Michel BA, Stucki G, Frey D, De Vathaire F, Vignon E, Bruehlmann P, et al. Chondroitins 4 and 6 sulfate in osteoarthritis of the knee: a randomized, controlled trial. Arthritis Rheum 2005;52:779-86.

4 Hochberg MC. Structure-modifying effects of chondroitin sulfate in knee osteoarthritis: an updated meta-analysis of randomized placebo-controlled trials of 2-year duration. Osteoarthritis Cartilage 2010;18 (suppl 1):S28-31.

5 Bruyere O, Pavelka K, Rovati LC, Gatterová J, Giacovelli $\mathrm{G}$, Olejarová M, et al. Total joint replacement after glucosamine sulfate treatment in knee osteoarthritis: results of a mean 8-year observation of patients from two previous 3-year, randomised, placebo-controlled trials. Osteoarthritis Cartilage 2008;16:254-60.

Cite this as: BMJ 2010;341:c6328

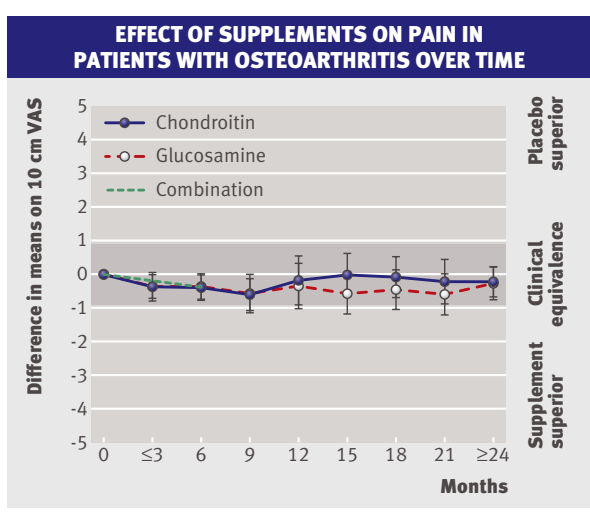

\section{Conclusions not supported by methods and results}

Wandel and colleagues produced another metaanalysis of glucosamine in osteoarthritis without new evidence when more comprehensive ones showed that the quality controlled product of glucosamine sulphate for prescription is effective. $^{1-4}$

Their statistical methods are so complex that many are mystified by whether the conclusions make sense. ${ }^{5}$ Indeed, we verified that a conventional approach gives identical results to their network meta-analysis with its poor trial selection, as shown by the high heterogeneity. ${ }^{6}$

They claim low heterogeneity in their Bayesian approach, while they used a prior distribution with strong emphasis on high heterogeneity. Moreover, they derive clinical relevance from artificial back transformations from the effect size and not from patient or study data. Consequently, they surprisingly raise the threshold for a clinically relevant effect size from 0.20 to 0.37 . Paracetamol has an effect size of 0.14 and non-steroidal anti-inflammatory drugs $0.29,{ }^{2}$ which is the same as glucosamine sulphate in high quality trials ${ }^{2}$ and the three long term trials with the prescription product in which heterogeneity disappears. ${ }^{4}$ These three show an effect size of 0.27 or $0.34,{ }^{4}{ }^{6}$ which Wandel and colleagues previously considered valuable. ${ }^{1}$
Network meta-analyses serve mainly to test the relative efficacy of drugs by indirect comparison: there is no such attempt here. The claim of using multiple observations is also misleading since it was done in only three out of seven studies; their inclusion does not change the results, as we tested.

These and other limitations ${ }^{6}$ mean that Wandel and colleagues' conclusions are not supported by their methods and results.

Giampaolo Giacovelli head, department of biostatistics giampaolo.giacovelli@rottapharm.com

Lucio C Rovati chief scientific officer, Rottapharm Madaus, 20052 Monza, Italy

Competing interests: GG and LCR are scientists from Rottapharm, maker of the proprietary formulation of prescription glucosamine sulphate. When contacted by

Wandel and colleagues to provide data on their trials that are included in the meta-analysis, they immediately agreed to do so, but they were never contacted again afterwards.

The full version of this response is available at www.bmj. com/content/341/bmj.c4675/reply\#bmj_el_242904.

1 Wandel S, Jüni P, Tendal B, Nüesch E, Villiger PM, Welton $\mathrm{NJ}$, et al. Effects of glucosamine, chondroitin, or placebo in patients with osteoarthritis of hip or knee: network metaanalysis. BMJ 2010;341:c4675. (16 September.)

2 Zhang W, Nuki G, Moskowitz RW, Abramson S, Altman RD, Arden NK, et al. OARSI recommendations for the management of hip and knee osteoarthritis: part III: Changes in evidence following systematic cumulative update of research published through January 2009. Osteoarthritis Cartilage 2010;18:476-99.

3 Towheed TE, Maxwell L, Anastassiades TP, Shea B, Houpt J, Robinson V, et al. Glucosamine therapy for treating osteoarthritis. Cochrane Database Syst Rev 2009;2:CD002946.

4 Reginster JY. The efficacy of glucosamine sulfate in osteoarthritis: financial and nonfinancial conflict of interest. Arthritis Rheum 2007;56:2105-10.

5 PocockSJ. Safety of drug-eluting stents: demystifying network meta-analysis. Lancet 2007;370:2099-100.

6 Reginster JY, Altman RD, Hochberg MC. Prescription glucosamine sulphate is effective in knee osteoarthritis. bmj.com 2010. www.bmj.com/content/341/bmj.c4675. full/reply\#bmj_el_242366.

Cite this as: $B M J$ J 2010;341:c6338

\section{Prescribed regimen is effective}

In a network meta-analysis of glucosamine in osteoarthritis, Wandel and colleagues did not separate the three long term trials of prescription glucosamine sulphate from those using over the counter products lacking evidence of efficacy or bioequivalence. ${ }^{1} \mathrm{~A}$ Cochrane review confirmed that the only product showing efficacy is prescription glucosamine sulphate $1500 \mathrm{mg}$ once daily. ${ }^{2}$

The authors diluted the efficacy of glucosamine sulphate in knee osteoarthritis by including two studies of glucosamine hydrochloride, a formulation discouraged in current guidelines ${ }^{4}$; they even attributed the McAlindon study to glucosamine sulphate when it was mostly hydrochloride. ${ }^{5}$ They also included a hip osteoarthritis study of a poor quality preparation. Inclusion of the Noack study is also questionable since duration was only one month. Moreover, use of divided doses (500 mg thrice daily) as in the glucosamine 
hydrochloride studies, impairs bioavailability compared with 1500 mg once daily. ${ }^{6}$

Including all seven studies in a conventional meta-analysis results in high heterogeneity $\left(1^{2}=63 \%\right)$, making interpretation of the modest effect size difficult. Conversely, heterogeneity is nil for the three prescription glucosamine sulphate long term trials of Reginster et al, Pavelka et al, Herrero-Beaumont et al, and the effect size is 0.27 for pain and 0.33 for function. ${ }^{3}$ Using one of the Bayesian approaches described by Wandel and colleagues, ${ }^{1}$ we found an effect size for pain of 0.34 (credible interval 0.08 to 0.61). These small to moderate effect sizes are superior to those of paracetamol and similar to those of non-steroidal anti-inflammatory drugs, which are universally recommended as first oral options for symptomatic osteoarthritis. ${ }^{4}$

The major limitations of Wandel and colleagues' analysis do not support the strong negative conclusions and are harmful to patients: rejecting an effective agent is both inappropriate and a disservice to the community.

Jean-Yves Reginster president and chair, Department of Public Health Sciences, University of Liège, 4000 Liège, Belgium jyreginster@ulg.ac.be

Roy D Altman professor of medicine, University of California, Los Angeles, 1000 Veterans Avenue, Los Angeles, CA 90024 , USA

Marc C Hochberg professor of medicine and epidemiology and public health, University of Maryland School of Medicine, Baltimore, MD 21201, USA

Competing interest: The authors have received research funding and lecturing fees from different pharmaceutical companies involved in the treatment of osteoarthritis, including glucosamine and chondroitin.

The full version of this response is available at www.bmj.com/ content/341/bmj.c4675.full/reply\#bmj_el_242366.

1 Wandel S, Jüni P, Tendal B, Nüesch E, Villiger PM, Welton NJ, et al. Effects of glucosamine, chondroitin, or placebo in patients with osteoarthritis of hip or knee: network meta-analysis. BMJ 2010;341:c4675. (16 September.)

2 Towheed TE, Maxwell L, Anastassiades TP, Shea B, Houpt J, Robinson V, et al. Glucosamine therapy for treating osteoarthritis. Cochrane Database Syst Rev 2009; 2:CD002946.

3 Reginster JY. The efficacy of glucosamine sulfate in osteoarthritis: financial and nonfinancial conflict of interest. Arthritis Rheum 2007:56:2105-10.

4 Zhang W, Moskowitz RW, Nuki G, Abramson S, Altman $\mathrm{RD}$, Arden NK, et al. OARSI recommendations for the management of hip and knee osteoarthritis: part II: OARSI evidence-based, expert consensus guidelines. Osteoarthritis Cartilage 2008;16:137-62. (Updated in Osteoarthritis Cartilage 2010;18:476-99.)

5 Vlad SC, LaValley MP, McAlindon TE, Felson DT. Glucosamine for pain in osteoarthritis: why do trial results differ? Arthritis Rheum 2007;56:2267-77.

6 Altman RD. Glucosamine therapy for knee osteoarthritis: pharmacokinetic considerations. Expert Rev Clin Pharmacol 2009;2:359-71.

Cite this as: $B M J$ 2010;341:c6335

\section{Authors' reply}

Pelletier and colleagues question the exclusion of small studies, ${ }^{1}$ although we have recently shown that small studies often distort results of meta-analyses of osteoarthritis trials, particularly for glucosamine and chondroitin trials. ${ }^{2}$ The issues of different types of glucosamine and differences in the quality and bioequivalence of preparations were examined in figure 3 of our report, without evidence to suggest that either will explain our results.

Giacovelli and Rovati suggest several errors in our classification of trials, ${ }^{3}$ which we were unable to confirm after careful re-examination of our data. The apparent misclassification of the trial by McAlindon regarding the type of glucosamine used is related to ambiguities in published information. ${ }^{4} 5$ The primary report states, "the switch from the Physiologics to Rotta glucosamine product occurred at enrolment of the 163rd participant." ${ }^{4}$ The description of the preparations confirms that the Physiologics preparation contained glucosamine sulphate. Since no correction of the original trial report is available to date we continue to adhere to our classification.

Contrary to the three letters, ${ }^{135}$ we have explored thoroughly the variation of effect of preparations over time. Figure 2 of our report and published results of accompanying statistical tests suggest that variation over time is no greater than that expected by chance alone $(P=0.93$ for interaction between treatment effect and time). With a tau-squared estimate of 0.04 , between trial heterogeneity was indeed low. We are unable to reproduce the estimate of Reginster and colleagues ${ }^{5}$ but emphasise that the large size of included studies means that $\mathrm{I}^{2}$ estimates may be unduly inflated, although the variation between trials is small. ${ }^{6}$

The cut-off points used to delineate the minimal clinically important difference were not based on Cohen's seminal work from the 1970s, ${ }^{7}$ as suggested by Pelletier et al, ${ }^{1}$ but on the median minimal clinically important difference found in recent studies in patients with osteoarthritis, as referenced in the methods section of our report. We agree that treatment effects of paracetamol are concerningly small, but effect sizes found in large trials of non-steroidal anti-inflammatory drugs (NSAIDs) and paracetamol using identical outcome definitions as those referred to in our report are larger than suggested by Giacovelli and Rovati $^{3}-0.38$ for oral NSAIDs (95\% confidence interval 0.49 to -0.27$)$ and -0.25 for paracetamol (0.39 to -0.11$)^{2}$

Observed treatment effects for both glucosamine and chondroitin compared with placebo are irrelevant to undetectable. With the observed differences in pain intensity of 0.3 to $0.5 \mathrm{~cm}$ between food supplements and placebo on a $10 \mathrm{~cm}$ visual analogue scale, the distribution of pain scores in patients receiving supplements and placebo are nearly identical. ${ }^{7}{ }^{8}$ Therefore, we maintain that it would be impossible, on the basis of the reported pain intensity at the end of a trial, to determine whether a patient was allocated to a food supplement or placebo.

Peter Jüni professor and head of division juni@ispm.unibe.ch

Eveline Nüesch research fellow,

Sven Trelle senior research fellow, Institute of Social and Preventive Medicine, University of Bern, and CTU Bern, Bern University Hospital, Switzerland

Competing interests: None declared.

1 Pelletier J-P, Hochberg MC, du Souich P, Kahan A, Michel BA. Effect size is encouraging. BMJ 2010;341:c6328.

2 Nüesch E, Trelle S, Reichenbach S, Rutjes AW, Tschannen B, Altman DG, et al. Small study effects in meta-analyses of osteoarthritis trials: meta-epidemiological study. BMJ 2010;341:c3515.

3 Giacovelli G, Rovati LC. Conclusions not supported by methods and results. BMJ 2010;341:c6338.

4 McAlindon T, Formica M, LaValley M, Lehmer M, Kabbara K. Effectiveness of glucosamine for symptoms of knee osteoarthritis: results from an internet-based randomized double-blind controlled trial. Am J Med 2004;117:643-9.

5 Reginster J-Y, Altman RD, Hochberg MC. Prescribed regimen is effective. $B M J$ 2010;341:c6335.

6 Rucker G, Schwarzer G, Carpenter JR, Schumacher M. Undue reliance on I(2) in assessing heterogeneity may mislead. BMC Med Res Methodol 2008;8:79.

7 Cohen J.Statistical power analysis for the behavioral sciences. 2nd ed. Lawrence Erlbaum, 1988.

8 Jüni P, Reichenbach S, Dieppe P. Osteoarthritis: rational approach to treating the individual. Best Pract Res Clin Rheumatol 2006;20:721-40.

Cite this as: $B M J$ 2010;341:c6340

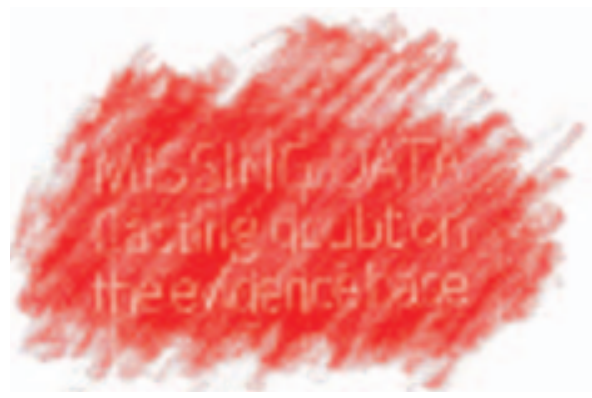

DATA OPENNESS

\section{Don’t forget preclinical science}

During the 1990s the pharmaceutical industry developed various atypical antipsychotic drugs that were contrasted favourably with older typical antipsychotics. Recent independent trials and meta-analyses indicate that the effects of the atypicals were exaggerated and that the existence of the drugs as a class is spurious, partly because of selective publication of clinical trial data. ${ }^{1-3}$

After these publications I recalled an indiscreet comment made many years ago by a senior preclinical scientist involved in developing an atypical, to the effect that atypicals did not differ from a low dose of haloperidol-the prototype older antipsychotic. I emailed him for his thoughts on the surprising recent clinical evidence. He indicated that he found the evidence unsurprising as his company had conducted extensive unpublished preclinical studies comparing an appropriate low dose of haloperidol with 
clozapine, the prototypical atypical, and observed no differences. Thus it is not only clinical trial data that are missing ${ }^{4}$ : preclinical data of substantial importance are also missing.

Ultimately, preclinical studies related to drug development and basic science are validated in terms of accepted clinical findings. Many studies in animals have been conducted with atypicals. Many of these will have been conducted because of the now contentious clinical findings. Missing clinical and preclinical data do not simply mislead clinicians: they mislead preclinical scientists also.

Andrew J Goudie reader in psychopharmacology, School of Psychology, Eleanor Rathbone Building, Liverpool University, L69 3BX, UK

ajg@liverpool.ac.uk

Competing interests: None declared.

1 Lieberman JA, Stroup TS, McEvoyJP, Swartz MS, Rosenheck RA, Perkins DO, et al; Clinical Antipsychotic Trials of Intervention Effectiveness (CATIE) Investigators. Effectiveness of antipsychotic drugs in patients with chronic schizophrenia. N Engl J Med 2005;353:1209-23.

2 Tyrer P, Kendall T. The spurious advance of antipsychotic drug therapy. Lancet 2009;373:4.

3 Leucht S, Corves C, Arbter D, Engel RR, Li C, Davis JM. Second-generation versus first-generation antipsychotic drugs for schizophrenia: A meta-analysis. Lancet 2009;373:31-41

4 Godlee F, Loder E. Missing clinical trial data: setting the record straight. BMJ 2010;341:c5641. (12 October.)

Cite this as: BMJ 2010;341:c6324

\section{Maintaining trust}

Trust in clinical research and its medical reporting lies at the heart of improving patient care whether the clinical research is sponsored by industry or academia.

Steinbrook and Kaiser assert that industry cannot be relied on to provide dispassionate evaluations of its own drugs and medical devices. ${ }^{1}$ They forget the rigorous internal and external control framework governing the conduct and reporting of clinical trials, including review by regulatory authorities and ethics committees.

They suggest greater access to trial databases. Investigators for GlaxoSmithKline studies can already review the entire database relating to the trial. We at GlaxoSmithKline are also open to further discussion of providing confidentially to medical journals the data on which manuscripts are based as part of the peer review process. Those with access to such data would have to be accountable for using them responsibly and for protecting patient confidentiality. Practical issues relating to the size and complexity of the databases would also need to be addressed.

We are committed to ensuring that the results of all the clinical studies evaluating our drugs are in the public domain. ${ }^{2}$ We welcome constructive discussions on ways trust can be strengthened further in the conduct and reporting of clinical research.
Pim Kon medical director medinfo@gsk.com Andrew Freeman director, medical advocacy and policy, GlaxoSmithKline UK, Stockley Park, Uxbridge, Middlesex UB111BT, UK

Competing interests: PK and AF are both employees of GlaxoSmithKline

1 Steinbrook R, Kassirer JP. Data availability for industry sponsored trials: what should medical journals require? BM/ 2010;341:C5391. (12 October.)

2 Strahlman E, Rockhold F, Freeman A. Public disclosure of clinical research. Lancet 2009;373:1319-20.

Cite this as: $B M J$ 2010;341:c6326

\section{CHILEAN MINERS}

\section{Let's hope doctor is misquoted}

I hope that the doctor looking after the psychological health of the miners was misquoted or mistranslated, but if he did say, "Now the men are starting to demand certain things, and we restrict others. We are measuring each other's strength" and that the miners would be rewarded if they cooperated but “If not, okay, you don't want to speak to psychologists? Perfect. That day you get no television; there is no music-because we administer these things" then something is amiss. ${ }^{1}$

As McCartney points out, ${ }^{1}$ the evidence from the literature is now clear. Single session psychological debriefing not only does not work, it probably increases the risk of subsequent psychological disorder. In 1999 when colleagues and I wrote the first Cochrane review on this, cited by McCartney, we concluded on the basis of available evidence that "compulsory debriefing must cease." This evidence has strengthened, not diminished, over time.

These men are not mentally ill. They have shown considerable resilience in the face of adversity, sustained by their own social networks and support. This must be respected and every effort made to ensure that this solidarity continues. A small number may develop mental health problems, including post-traumatic stress disorder. At such a time, evidence based psychological therapies should be made available, but only on the basis of consent, never coercion. ${ }^{2}$

There is no justification for treating the 33 miners as mentally ill, or even likely to become so, not least because this could become a self fulfilling prophecy. Instead, better to assume that they are the robust, resilient people that they have been to date, maintain a discrete supportive contact, and be available if and when a few do need psychological help.

Simon Wessely professor of psychological medicine, Institute of Psychiatry, King's College London, London, UK simon.wessely@kcl.ac.uk Competing interests: None declared.
1 McCartney M. What's keeping the Chilean miners down? BM/ 2010;341:c5860. (21 October.)

2 Stein D, Seedat S, Iversen A, Wessely S. Posttraumatic stress disorder: medicine and politics in the aftermath of trauma. Lancet 2007;369:139-44.

Cite this as: $B M / 2010 ; 341: c 6321$

\section{JOURNALS AND CONSENT FORMS}

\section{Policy needs to be revisited}

Consent should be obtained before publishing case reports. ${ }^{1}$ Signed consent forms include patient's name and the manuscript title, which often states the illness. Several UK journals insist that consent forms are sent to their editorial offices.

In the UK, processing of personal data is governed by the Data Protection Act 1998. ${ }^{2}$ Disclosure of sensitive personal data needs the explicit consent of the patient. ${ }^{2}$ But such consent is different from the disclosure of patients' names to journals, and this matter needs further clarification. Case reports have a high rejection rate so large amounts of named health data are accessible at publishing houses for no good reason.

We don't understand how a signed consent form is of value as regards its authenticity. We believe journals should place more trust in authors' attestation of consent. Forms could be archived in the patient's records or possibly with the Caldicott Guardian. If not, forms should make it explicit to patients that they are giving permission for the clinical material to be published and for the transfer of their personal verification. Patients should be advised that their sensitive and named personal data will be stored by the publisher indefinitely and would be accessible to staff.

Authors are responsible for data transfer but journals should revisit their requirements that facilitate the process.

Abhijit M Bal consultant microbiologist, Crosshouse Hospital, Kilmarnock KA2 OBE, UK

abhijit.bal@nhs.net

Andrew Collier consultant physician, Ayr Hospital, Ayr KA6 6DX, UK

Al Dowie senior university teacher in medical ethics, law, and risk, Section of General Practice and Primary Care, University of Glasgow, Glasgow G12 9LX, UK Sujoy Ghosh consultant diabetologist, AMRI Institute of Diabetes and Hormonal Disorders, Kolkata 700029, India Competing interests: AMB, AC, and SG withdrew a case report from a mainstream journal published in the UK after refusing to transfer the consent form. AD has no conflict of interest to declare.

1 Smith J. Patient confidentiality and consent to publication. BM/ 2008;337:a1572.

2 Data Protection Act 1998. www.legislation.gov.uk/ ukpga/1998/29/contents.

3 Information Commissioner's Office. Use and disclosure of health data: guidance on the application of the Data Protection Act. 2002. www.ico.gov. uk/upload/documents/library/data_protection/ practical_application/health_data_-_use_and_ disclosure001.pdf.

Cite this as: BMJ 2010;341:c6147 